\title{
Microstructure-Property Relations in Melt Processed and Spark Plasma Sintered Ceramic Waste Forms
}

\author{
B. M. Clark ${ }^{1}$, P. Tumurugoti ${ }^{1}$, S. K. Sundaram ${ }^{1}$, J. W. Amoroso ${ }^{2}$, J. C. Marra ${ }^{2}$, and K. S. Brinkman ${ }^{3}$ \\ ${ }^{1}$ Kazuo Inamori School of Engineering, The New York State College of Ceramics, Alfred University, \\ Alfred, NY, 14802 \\ ${ }^{2}$ Savannah River National Laboratory, Aiken, SC, 29808 \\ ${ }^{3}$ Department of Materials Science and Engineering, Clemson University, Clemson, SC 29634
}

The use of nuclear power to generate electricity necessitates methods to immobilize waste generated from those processes. There are many proposed waste form technologies for the storage of nuclear waste such as vitrification, hot isostatic pressing, melt formation, and spark plasma sintering (SPS). Titanatebased ceramic waste forms specifically SYNROC [1] and derivative materials have been widely studied for their potential to accommodate a large variety of radionuclides. The major phases targeted in SYNROC compositions are zirconolite $\left(\mathrm{CaZrTi}_{2} \mathrm{O}_{7}\right)$, hollandite $\left(\mathrm{Ba}_{\mathrm{x}} \mathrm{Cs}_{\mathrm{y}} \mathrm{Al}_{2 \mathrm{x}+\mathrm{y}} \mathrm{Ti}_{8-2 \mathrm{x}-\mathrm{y}} \mathrm{O}_{16}\right)$, and perovskite/pyrochlore $\left(\mathrm{CaTiO}_{3} / \mathrm{A}_{2} \mathrm{~B}_{2} \mathrm{O}_{7}\right.$, where $\mathrm{A}$ and $\mathrm{B}$ are different $3+$ or $4+$ cations). Zirconolite and perovskite/pyrochlore are targeted to immobilize the majority of actinides, while fission products (Cs and $\mathrm{Sr}$ ) are immobilized in hollandite phases.

The method of processing a ceramic waste form affects the final properties such as chemical durability and radiation resistance. Joule-heated melters are already being used for the vitrification of High Level Waste (HLW) in many countries, which allows for high throughput of waste forms. Extensive reported literature and knowledge in the area of melting and solidification of materials in general help prediction of phase assemblage and performance of the waste form. Disadvantages of melt formation are the potential volatilization of waste elements at the elevated temperatures needed for melting to occur and difficulty in controlling the cooling rate, hence the phase assemblages in a multi-phase ceramic waste form.

SPS is of interest as an alternative formation technique because of the comparatively short processing time (a total of about 20 minutes) that is required to achieve a dense ceramic with close to near-netshape microstructure. The short processing times (along with self-contained sample inside the die) can reduce the volatilization of waste elements. Uniaxial pressure and a DC current are simultaneously applied to a graphite die containing the powder sample. The current generates resistive heating of the graphite die, which creates fast heating rates of up to $1000^{\circ} \mathrm{C} / \mathrm{min}$. The SPS processing environment is inherently reducing, as it utilizes a graphite die, and is capable of producing high-density samples compared to melt processing. SPS is a batch process limited by the small throughput that can be obtained with current instrument configurations and carbon diffusion from the die into the sample occurs at elevated temperatures.

Compositions of multiphase and single phase hollandite, with metal oxide additions of $\mathrm{Cr}, \mathrm{Al}$, and $\mathrm{Fe}$ (designated CAF-MP,SP) and Cr (designated Cr-MP,SP), waste forms based on simulated waste streams compositions generated from the Fuel Cycle Reseach and Development (FCR\&D) Separation and Waste Form campaign aqueous separation process were developed by Savannah River National Laboratory (SRNL). Oxide and carbonate precursors were blended together via ball milling and subjected to melt or SPS processes. Melting was performed in a tube furnace by placing the loosely packed mixed powders 
into an alumina crucible and heating the furnace to $1500-1550^{\circ} \mathrm{C}$ at a rate of $5^{\circ} \mathrm{C} / \mathrm{min}$, holding for 30 minutes, and allowing to furnace cool to room temperature. The solidified contents were removed from the crucible and used for characterization. Reaction via SPS was carried out using the schedule as follows: a heating rate of $100^{\circ} \mathrm{C} / \mathrm{min}$ for both samples to a maximum temperature of $1000^{\circ} \mathrm{C}$ or $1040^{\circ} \mathrm{C}$, a hold time for 3 and 5 minutes for MP and SP samples respectively, and a cooling rate of $100^{\circ} \mathrm{C} / \mathrm{min}$. The samples were subjected to $54 \mathrm{MPa}$ pressure throughout the reaction.

Each processing method produced a similar phase assemblage (observed with x-ray diffraction), but The microstructures were different, as would be expected given the experimental differences (Figure 1). In the SPS sample, hollandite formed the matrix of the sample with the remaining phases interdispersed in phase fields ranging from $<1 \mu \mathrm{m}$ to $\sim 10 \mu \mathrm{m}$. Energy dispersive spectrometry (EDS) measurements confirmed the presence of Cs, a volatile element in waste streams, in the SPS sample. Melt processed samples contained larger grains $(10-20 \mu \mathrm{m})$ of specific phases. Significant porosity was observed in the microstructure. Cs was not detected from EDS. A large surface area to volume ratio of powders processed in the alumina crucibles might have enhanced the volatilization of Cs.

Standard chemical leaching tests were carried out at SRNL as a preliminary technique to determine the aqueous leaching durability of samples processed using the two methods. The samples were ground and sealed in stainless steel vessels with $15 \mathrm{~mL}$ of Type-I ASTM water and placed in an oven at $90^{\circ} \mathrm{C}$ for 7 days. The resulting solution was filtered, acidified and then analyzed by inductively coupled plasma atomic emission spectroscopy (ICP-AES) to calculate normalized release rates of specific ions.

\section{References}

[1] A.E. Ringwood et al, Nature 278 (1979), p. 219-223.

[2] The authors would like to acknowledge the US Department of Energy (DOE) Nuclear Energy University Program (NEUP) for supporting this project, and guidance from Dr. John D. Vienna from Pacific Northwest National Laboratory (PNNL). SKS acknowledges the Inamori Professorship supported by the Kyocera Corporation

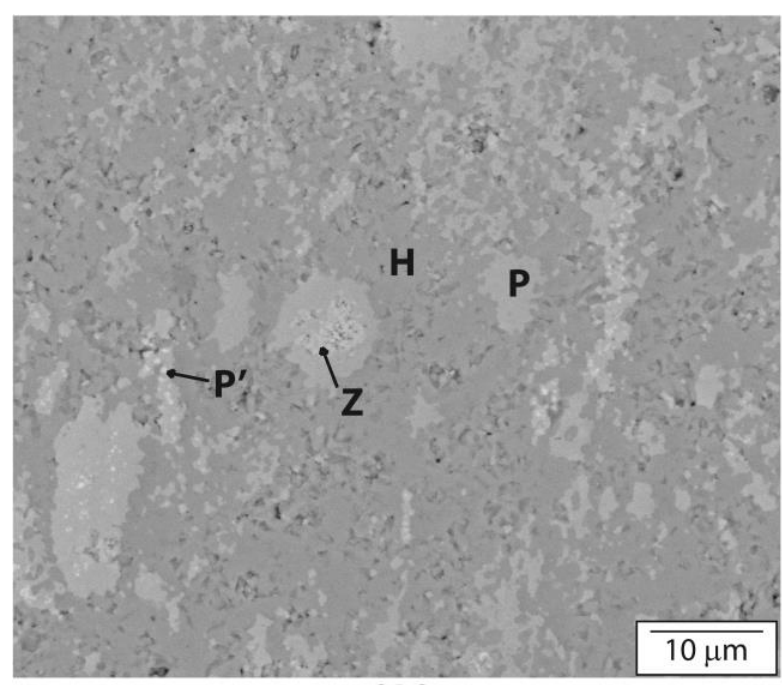

SPS

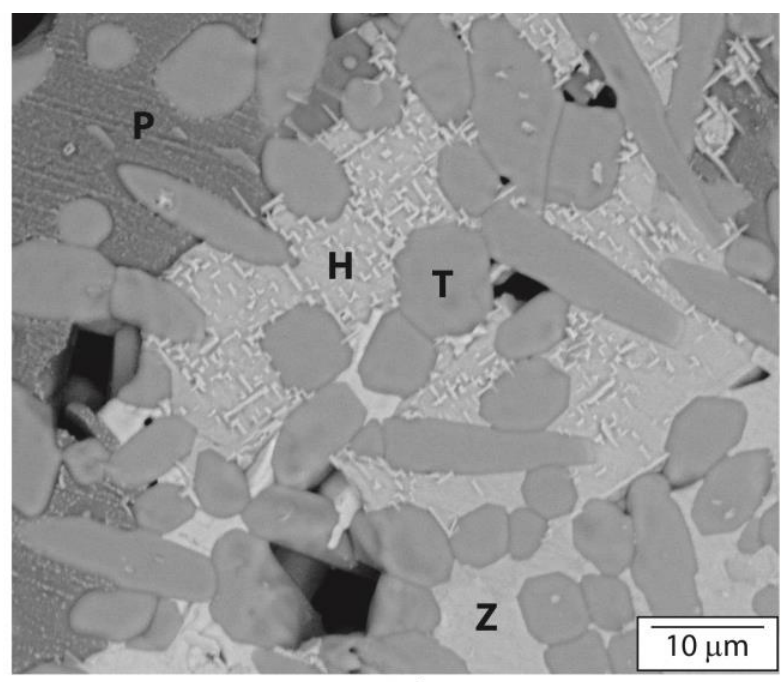

Melt

Figure 1. Microstructures of SPS and melt processed Cr-MP samples with indicated phase fields, $\mathrm{H}$ hollandite, $\mathrm{P}$ and $\mathrm{P}^{\prime}$ - perovskite, $\mathrm{Z}-\mathrm{ZrTiO}_{4}, \mathrm{~T}-\mathrm{TiO}_{2}$ 